\title{
Study on Permeation Grouting Using Cement Grout In Sandy Soil
}

\author{
P. Dayakar ${ }^{1}$, K. Venkat Raman ${ }^{1}$, Dr. K.V.B. Raju ${ }^{2}$ \\ ${ }^{1}$ Department of Civil Engineering, Bharath University, Selaiyur, Chennai, Tamilnadu, India. \\ ${ }^{2}$ Director, GITAM University, Bengaluru.
}

\begin{abstract}
Grouting is the process of ground improvement techniques which is used to improvise the foundation where there is loose state of the soil. Grouting can be classified as permeation grouting, compaction grouting or hydraulic fracturing. Permeation grouting is an effective way to send the grout into the ground without disturbing the soil structure. In this investigation, an attempt is made to study the effect of cement grout in improving the bearing capacity of the sandy soil. Cement grout with different ratio of 10:1 (Water: Cement), 9:1, 8:1, 7:1, 6:1, 5:1, 4:1 are injected into the soil. Grouting experiment is performed with perforated PVC pipe in a tank of $20 \mathrm{~cm} \times 20 \mathrm{~cm} \times 20 \mathrm{~cm}$ sandy soil. To study the improvement in the strength property of the grouted soil the plate load test is performed with $5 \mathrm{~cm} \times 5 \mathrm{~cm}$ plate on the grouted sand after 3 days curing and 7 days curing. The experimental results revealed that the increase in cement content increases load carrying capacity of the sandy soil.
\end{abstract}

\section{Introduction}

Grouting is the process of ground improvement attained by injection of a fluid like material that is capable of forming a gel and binding the soil particles. Grouting can be permeation grouting, compaction grouting or hydraulic fracturing. Permeation grouting involves the free flow of grout into the soil voids with minimal effect. Grout materials may be solution grouts or suspension grouts. Permeation grouting technique is generally used to reduce ground permeability and control ground water flow, but it can also be used to strengthen and stiffen the ground (CIRIA, 2000). Suat Akbulut et al. (2002) concluded that the soil particle size and the cement maximum particle size have important effects on the successful grouting". Purbi Sen et al. (2011) concluded that, it is desirable to use a mixture of lime and cement or pretreatment of soil with lime before use of cement or use of lime only if possible. Costas.A.Anagnostopoulos, (2005) has concluded that the combination of such material with cement in grouting purpose with respect to water cement ratio contributes significantly to the improvement of grouted soil.

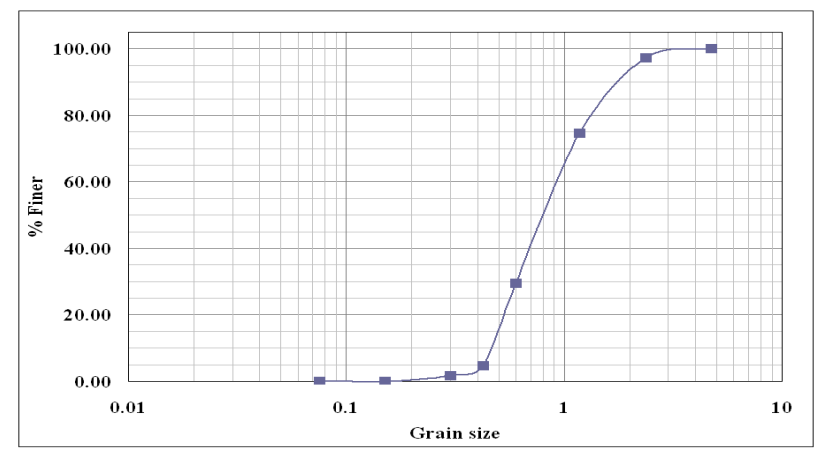

Fig. 1 Grain size distribution curve of the sand

\section{Materials}

Table 1 Properties of the sand
\begin{tabular}{|l|c|}
\hline \multicolumn{1}{|c|}{ Properties } & Values \\
\hline Specific Gravity & 2.6 \\
\hline Coarse Sand $\%$ & 25 \\
\hline Medium Sand, \% & 70 \\
\hline Fine Sand, \% & 5 \\
\hline $\mathrm{D}_{60}, \mathrm{~mm}$ & 0.9 \\
\hline $\mathrm{D}_{30}, \mathrm{~mm}$ & 0.6 \\
\hline $\mathrm{D}_{10}, \mathrm{~mm}$ & 0.47 \\
\hline $\mathrm{C}_{\mathrm{c}}$ & 0.85 \\
\hline $\mathrm{C}_{\mathrm{u}}$ & 1.91 \\
\hline $\mathrm{e}_{\operatorname{mas}}$ & 0.71 \\
\hline $\mathrm{S}_{\min }$ & 0.48 \\
\hline Classification & $\mathrm{SP}$ \\
\hline
\end{tabular}


Locally available river sand is utilized for this study and the properties of the sand are given in table 1 . The grain size distribution curves of these fractions are shown in fig.1. The cement used for the study is 43 grades Portland Puzzolona Cement, the properties of which are given in table 2.

Table 2 Properties of the cement

\begin{tabular}{|l|c|}
\hline \multicolumn{1}{|c|}{ Properties } & Values \\
\hline Grade & PPC \\
\hline Specific Gravity & 3.15 \\
\hline Fineness, \% & 95 \\
\hline Consistency, \% & 35 \\
\hline Initial Setting Time, min & 30 \\
\hline
\end{tabular}

\section{Methodology}

For preparing permeation grouted samples, a tank of size $20 \mathrm{~cm} \times 20 \mathrm{~cm} \times 20 \mathrm{~cm}$ is fabricated with polycarbide sheet. The sand to be grouted is filled in the tank at the loosest unit weight of $17.7 \mathrm{kN} / \mathrm{m}^{3}$, corresponding to initial void ratio $\left(\mathrm{e}_{\max }\right)$ of 0.71 . Fig. 2 shows the tank and pipe setup for grouting process. Four PVC Pipes of $20 \mathrm{~mm}$ diameter are used for the grouting, with perforations in surface of the pipe with $3 \mathrm{~mm}$ diameter which are 36 in number for each pipe. The bottom of the PVC pipe is plugged so as to disperse the grout circumferentially and make the grouting more effective.

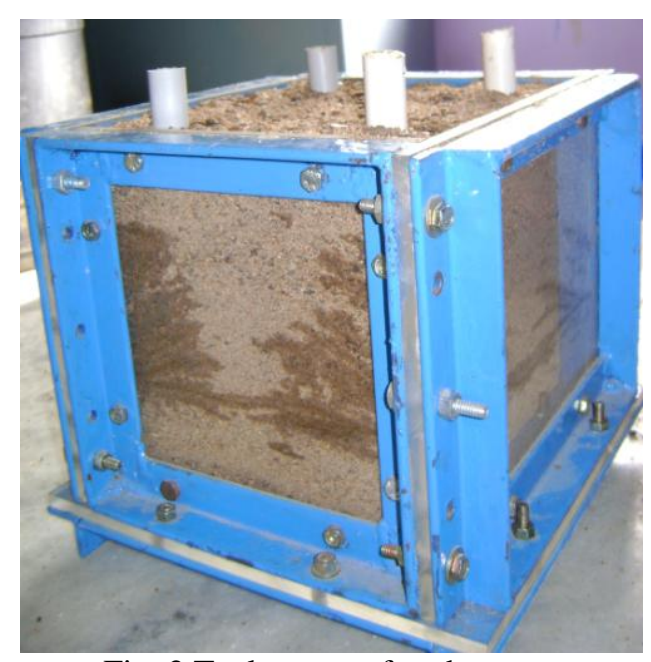

Fig. 2 Tank set up after the grout

The grout which is prepared at water: cement ratio of 10:1, and agitated well to get uniform grout solution is poured into the four PVC pipes uniformly. In order to reduce the chances of segregation of the grout, the grout is agitated and then poured. The procedure is repeated for water: cement ratios of 9:1, 8:1, 7:1, 6:1, 5:1 and 4:1. The Viscosity of the cement grout is determined with Marsh funnel viscosity test (ASTM D691004).The grouted sample was kept under moist condition for a curing period of 3 days and 7 days. The notation followed for the mix proportion is given in table 3 .

Table 3 Mixing proportions of Grout and their notations

\begin{tabular}{|c|c|c|}
\hline Notation & Water & Cement \\
\hline G1 & 10 & 1 \\
\hline G2 & 9 & 1 \\
\hline G3 & 8 & 1 \\
\hline G4 & 7 & 1 \\
\hline G5 & 6 & 1 \\
\hline G6 & 5 & 1 \\
\hline G7 & 4 & 1 \\
\hline
\end{tabular}




\section{Experimental Set Up}

The grouted sand which is cured for 3 days is placed in the Triaxial loading frame to perform the plate load test. The plate is of $5 \mathrm{~cm} \times 5 \mathrm{~cm}$ and $4 \mathrm{~mm}$ thick. Fig 4 shows the experimental setup of performing the plate load test. Data logger is used to monitor the load from the load cell and displacement from the LVDT. Care is taken to load the grouted sand specimen centrally.

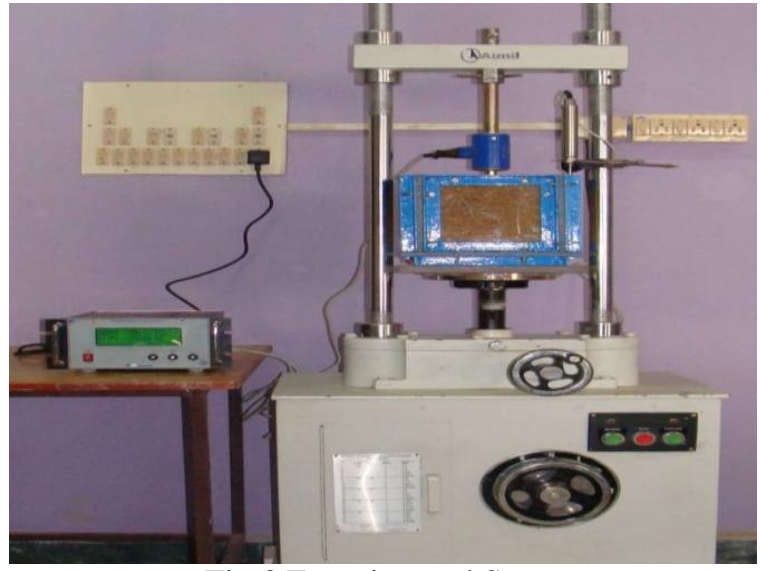

Fig.3 Experimental Setup

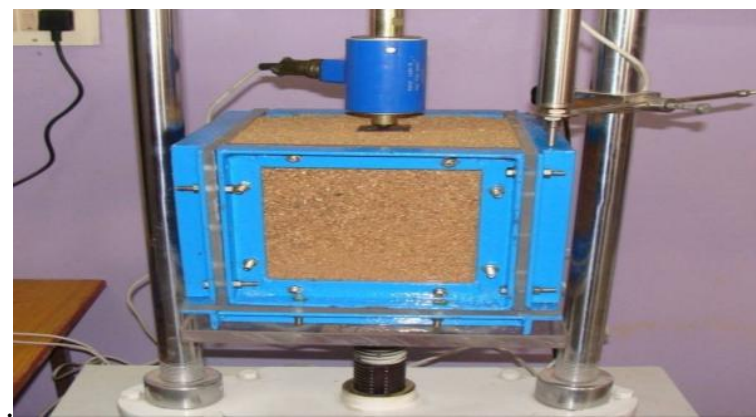

Fig.4 Plate Load test

\section{Results And Discussions}

To determine the increase in the strength of the grouted sand, the plate load test is conducted in the same tank with sand loosely filled without grouting. Fig 5 shows the load settlement curve for the sand without grouting, the ultimate load being $0.09 \mathrm{kN}$. Then sand bed prepared at a unit weight of $13.1 \mathrm{kN} / \mathrm{m}^{3}$ (in the loosest state) is grouted with the help pvc pipes and is cured for a period 3 days and 7 days. The efficiency of grouting mainly depends upon the penetration of cement grout through the pores of sand. Therefore the plate load test determination is very much necessary to assess the increase in strength of the grouted soil mass.

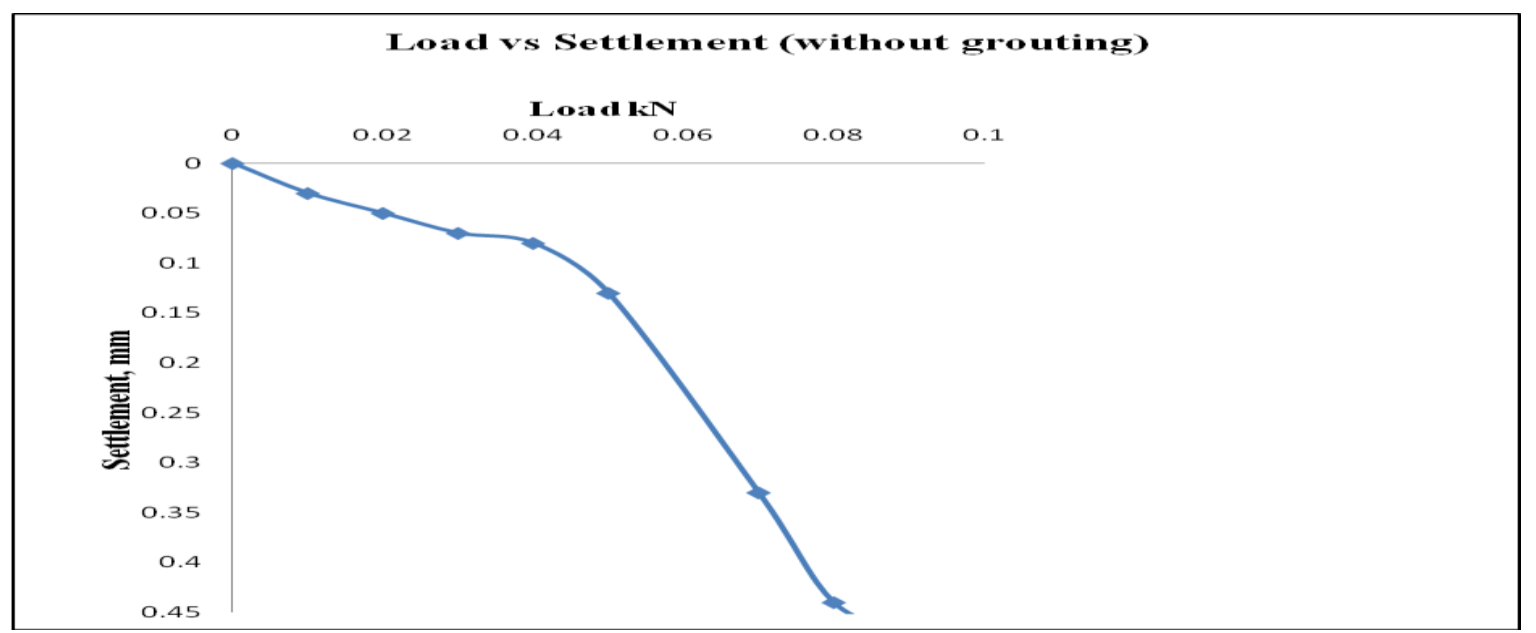

Fig.5 Load Settlement curve for the loose state of soil without grouting 
Fig. 6 and 7 show the load settlement curve for varying water cement ratios from 10: 1 to 4:1 for 3 days curing of permeation grouted sand in the loose state. From the graph it can seen that as the grout ratio decreases the ultimate load increases by 1.2 to 14 times more than the sand without grouting for 3 days curing. In case of 7 days curing the increase in ultimate load is 7 to 14.5 times more than the sand without grouting.

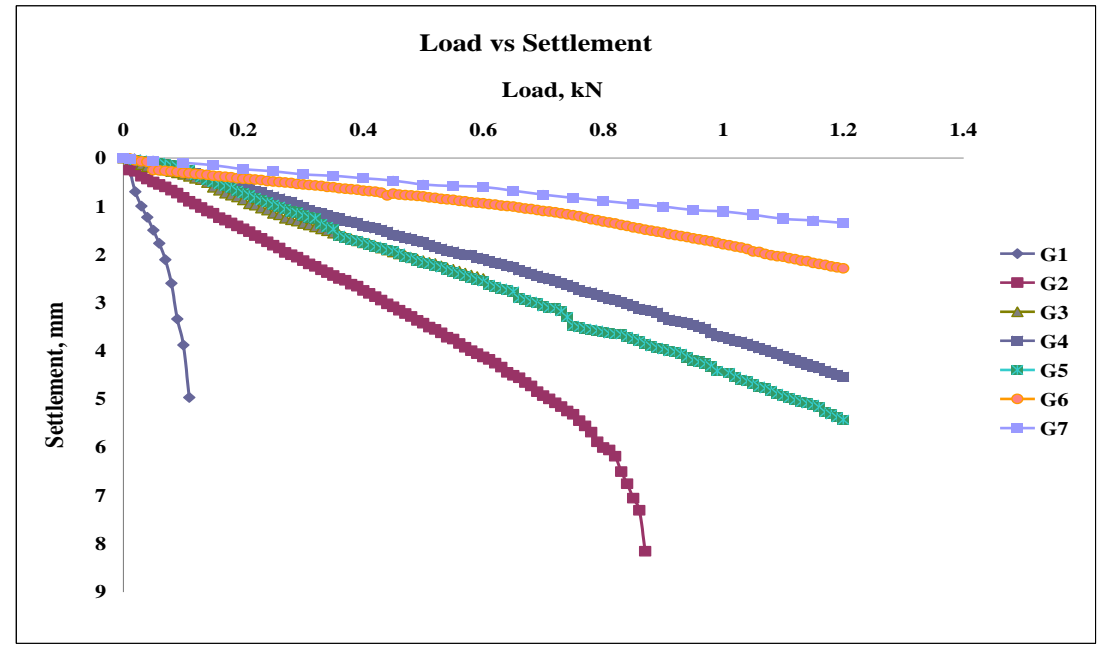

Fig. 6 Load Settlement curve - Loose State; 3 days Curing

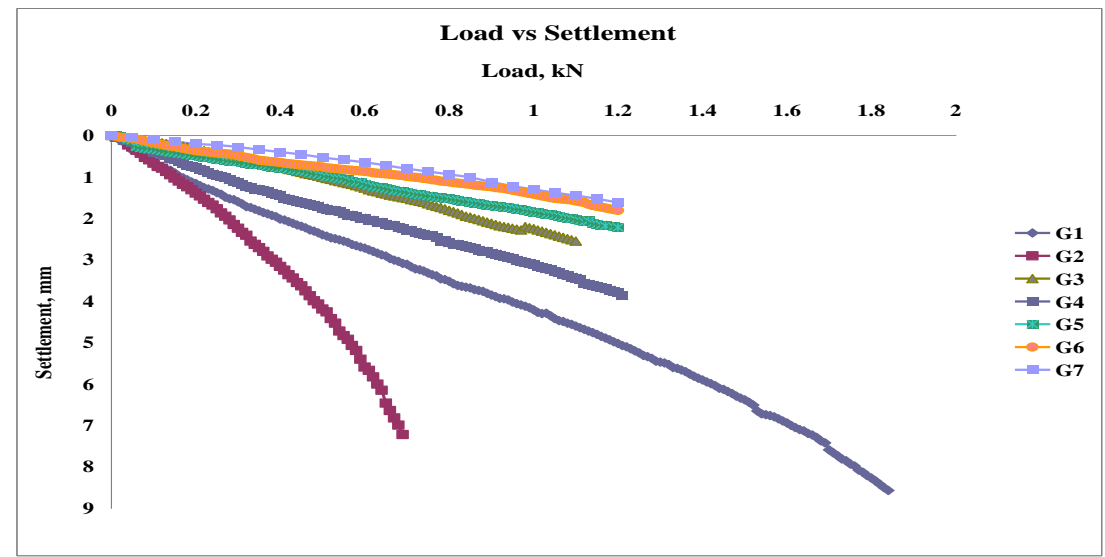

Fig. 7 Load Settlement curve - Loose State; 7 days Curing

Fig. 8 and 9 show the load settlement curve for varying water cement ratios from 10: 1 to $4: 1$ for 3 days curing of permeation grouted sand in the medium dense state. From the graph it can seen that as the grout ratio decreases the ultimate load increases by 11 to 16 times more than the sand without grouting for 3 days curing. In case of 7 days curing the increase in ultimate load is 12 to 21 times more than the sand without grouting.

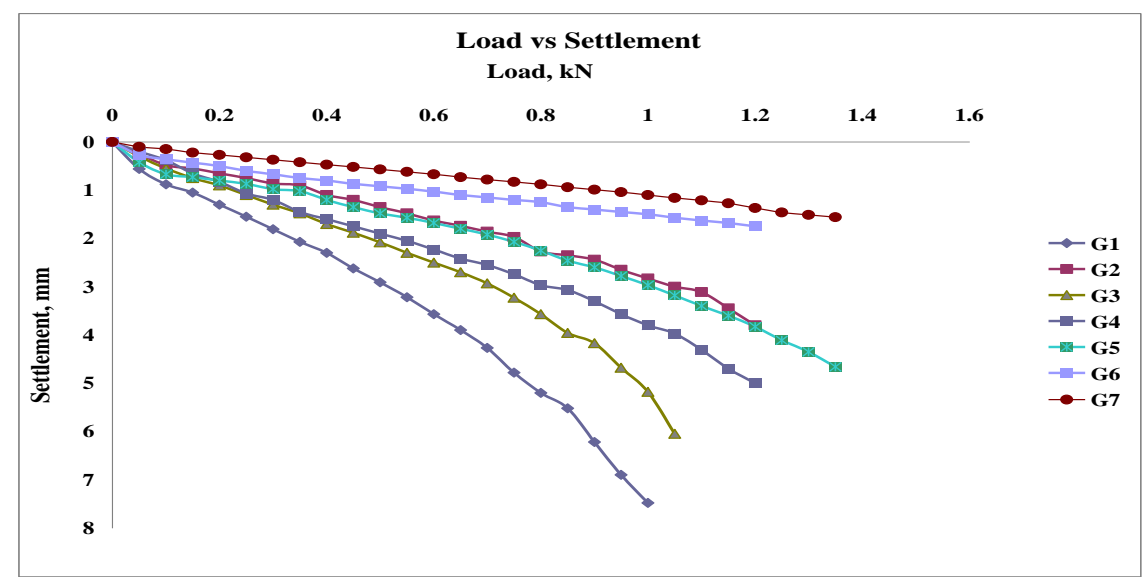

Fig. 8 Load Settlement curve - Medium dense State; 3 days Curing 


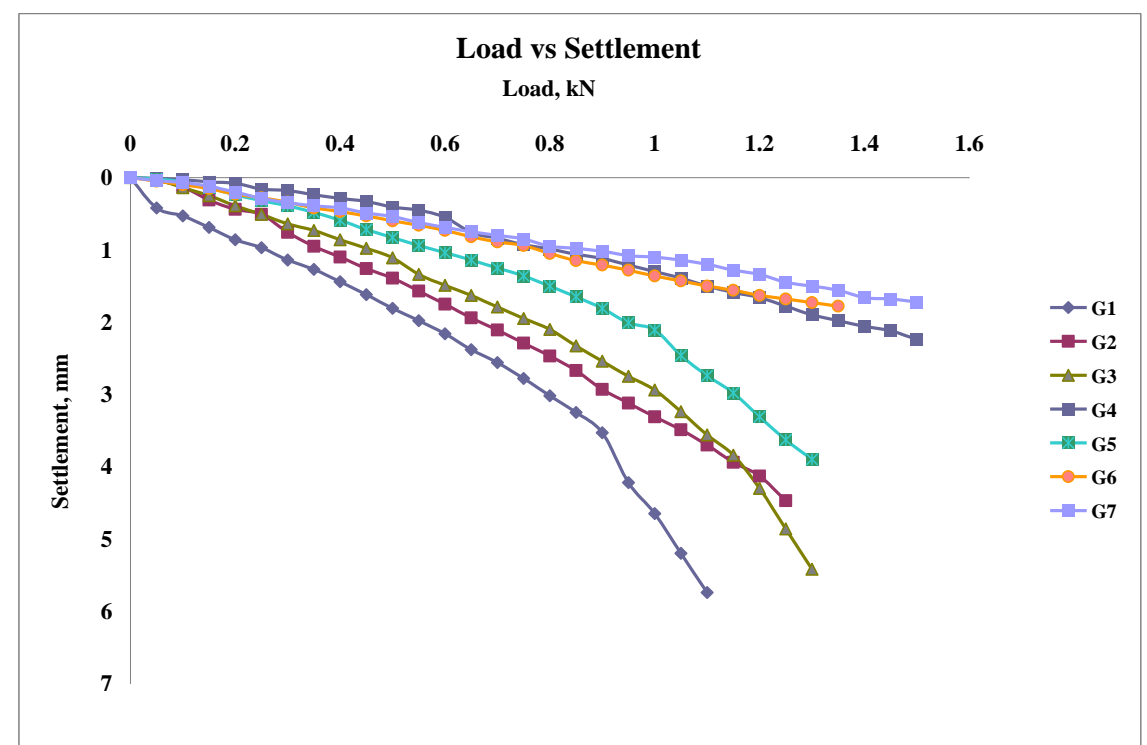

Fig. 9 Load Settlement curve - Medium dense State; 7 days Curing

The ultimate load determined from the load settlement curve for various grout ratios with different curing period of 3 days and 7 days is tabulated in table 4 for the grouting in loose state.

Table 4 Test Results of Cement Grout in Loose state

\begin{tabular}{|c|c|c|c|}
\hline \multirow{2}{*}{ Grout Ratio } & Funnel Viscosity & \multicolumn{2}{|c|}{ Ultimate Load, kN } \\
\cline { 3 - 4 } & $(\mathbf{s})$ & 3 days Curing & $\mathbf{7 ~ d a y s ~ C u r i n g ~}$ \\
\hline $10: 1$ & 32 & 0.11 & 0.69 \\
\hline $9: 1$ & 31 & 0.60 & 0.84 \\
\hline $8: 1$ & 26 & 0.87 & 1.1 \\
\hline $7: 1$ & 24 & 1.2 & 1.21 \\
\hline $6: 1$ & 22 & 1.21 & 1.23 \\
\hline $5: 1$ & 17 & 1.25 & 1.26 \\
\hline $4: 1$ & 14 & 1.28 & 1.3 \\
\hline
\end{tabular}

Table 5 show the ultimate load determined from the load settlement curve for various grout ratios with different curing period of 3 days and 7 days for the grouting in medium dense state.

Table 5 Test Results of Cement Grout in medium dense state

\begin{tabular}{|c|c|c|c|}
\hline \multirow{2}{*}{ Grout Ratio } & \multirow{2}{*}{$\begin{array}{c}\text { Funnel Viscosity } \\
(\mathbf{s})\end{array}$} & \multicolumn{2}{|c|}{ Ultimate Load, kN } \\
\cline { 3 - 4 } & 32 & 1 & 3 days Curing \\
$\mathbf{7}$ days Curing \\
\hline $10: 1$ & 31 & 1.2 & 1.1 \\
\hline $9: 1$ & 26 & 1.25 & 1.25 \\
\hline $8: 1$ & 24 & 1.31 & 1.5 \\
\hline $7: 1$ & 22 & 1.35 & 1.61 \\
\hline $6: 1$ & 17 & 1.37 & 1.73 \\
\hline $5: 1$ & 14 & 1.41 & 1.92 \\
\hline $4: 1$ & & & \\
\hline
\end{tabular}

From the values of table 4 and 5 a plot is made between void ratio and ultimate load. Fig. 10 shows that as the void ratio increases the ultimate load decreases. 


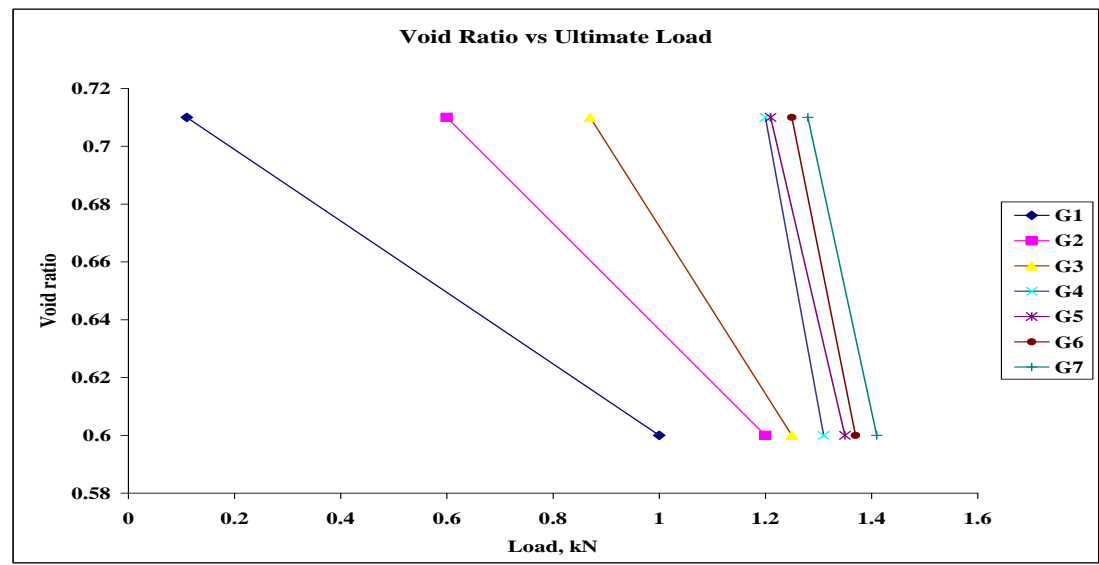

Fig. 10 Relationship between void ratio and ultimate load - 3 days Curing

From the values of table 4 and 5 a plot is made between funnel viscosity and ultimate load. Fig. 11 shows that as the funnel viscosity increases the ultimate load increases.

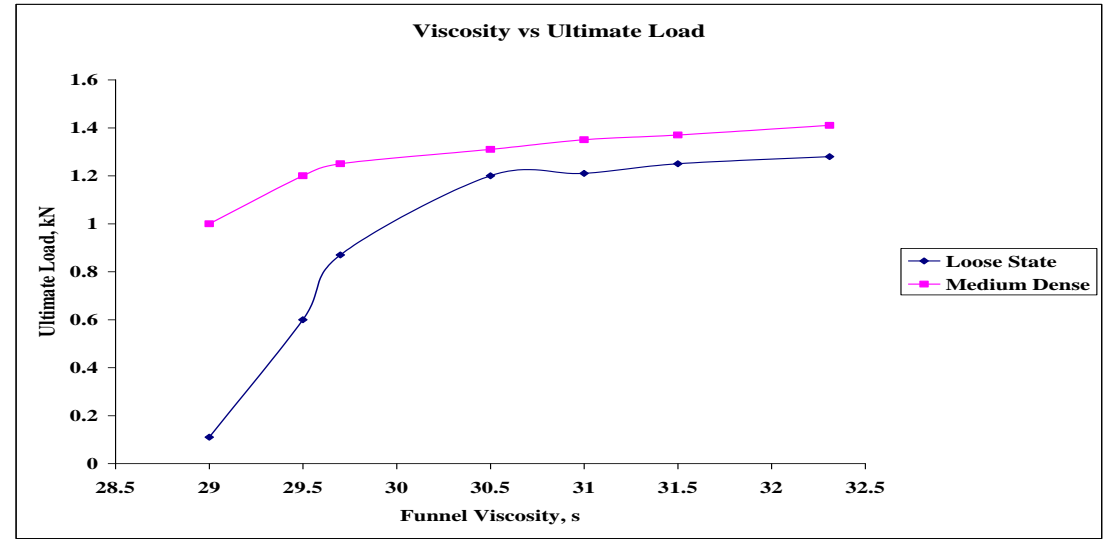

Fig. 11 Relationship between Funnel viscosity and ultimate load - 3 days curing

\section{Conclusions}

The efficiency of grouting mainly depends upon the penetration of cement grout through the pores of sand. The following conclusions are drawn from the plate load tests. It can be seen that as the grout ratio decreases the ultimate load increases by 1.2 to 14 times for 3 days curing and 7 to 14.5 times for 7 days curing in case of loose state of soil (void ratio - 0.71). Whereas in the case of medium dense state ( void ratio - 0.6) it can be seen that as the grout ratio decreases the ultimate load increases by 11 to 16 times for 3 days curing and 12 to 21 times for 7 days curing. Also it can be concluded that as the void ratio and grout ratio decrease the ultimate load increases. Moreover the funnel viscosity of the grout solution shows that increase in the viscosity increases the ultimate load.

\section{References}

[1] Suat Akbulut and Ahmet Saglamer (2002), "Estimating the groutability of granular soils: a new approach", Tunnelling and Underground Space Technology, 17, pp $371-380$

[2] Purbi Sen, Sina Kazemian, Bujang.B.K.Huat , (2011), "Assesment and Comparision of grouting and Injection Method in Geotechnical Engineering”, European Journal of Scientific Research, Vol 27 No. 2 (2011), pp 234-247.

[3] Dr. Abdel-Monem Moussa, Dr. Fatma El-Zaharaa Baligh, Dr. Tahia Abdel-Monem Awad, Asmaa El- Rokh (2007), "Sandy soil improvement using grouting", $12^{\text {th }}$ ICSCE, Cairo, Egypt.

[4] Costas A. Anagnostopous (2005), "Laboratory study of an injected granular soil with polymer grouts", Tunnelling and Underground Space Technology, 20, pp 525 - 533.

[5] Standard test method for Marsh Funnel Viscosity of clay slurries (2004), ASTM, D6910-04. 